BMC

Evolutionary Biology

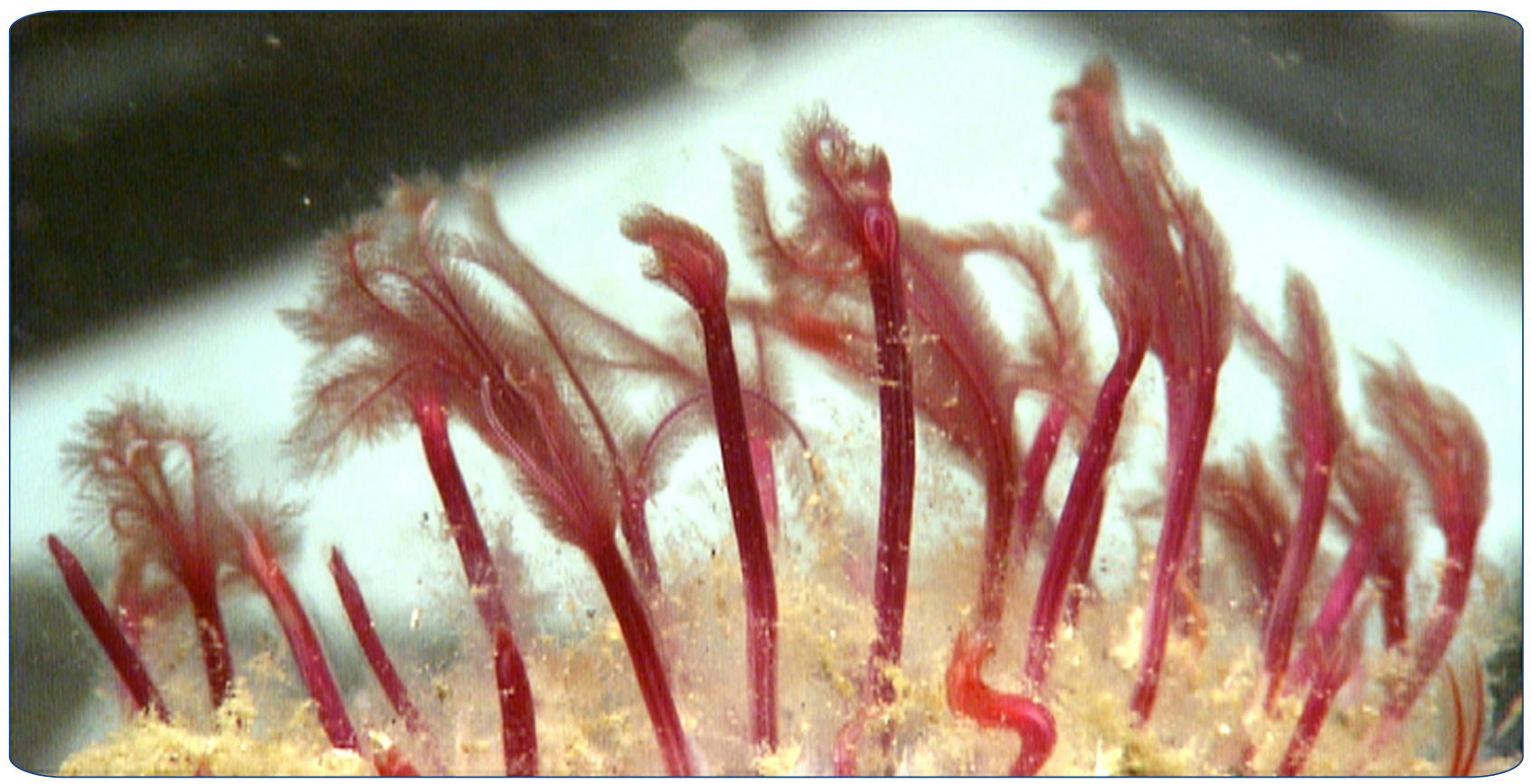

Temporal variation and lack of host specificity among bacterial endosymbionts of Osedax bone worms (Polychaeta: Siboglinidae)

Salathé and Vrijenhoek 


\title{
Temporal variation and lack of host specificity among bacterial endosymbionts of Osedax bone worms (Polychaeta: Siboglinidae)
}

\author{
Rahel M Salathé ${ }^{1,2}$ and Robert C Vrijenhoek ${ }^{1 *}$
}

\begin{abstract}
Background: Osedax worms use a proliferative root system to extract nutrients from the bones of sunken vertebrate carcasses. The roots contain bacterial endosymbionts that contribute to the nutrition of these mouthless and gutless worms. The worms acquire these essential endosymbionts locally from the environment in which their larvae settle. Here we report on the temporal dynamics of endosymbiont diversity hosted by nine Osedax species sampled during a three-year investigation of an experimental whale fall at 1820-m depth in the Monterey Bay, California. The host species were identified by their unique mitochondrial COI haplotypes. The endosymbionts were identified by ribotyping with PCR primers specifically designed to target Oceanospirillales.

Results: Thirty-two endosymbiont ribotypes associated with these worms clustered into two distinct bacterial ribospecies that together comprise a monophyletic group, mostly restricted to deep waters (>1000 m). Statistical analyses confirmed significant changes in the relative abundances of host species and the two dominant endosymbiont ribospecies during the three-year sampling period. Bone type (whale vs. cow) also had a significant effect on host species, but not on the two dominant symbiont ribospecies. No statistically significant association existed between the host species and endosymbiont ribospecies.

Conclusions: Standard PCR and direct sequencing proved to be an efficient method for ribotyping the numerically dominant endosymbiont strains infecting a large sample of host individuals; however, this method did not adequately represent the frequency of mixed infections, which appears to be the rule rather than an exception for Osedax individuals. Through cloning and the use of experimental dilution series, we determined that minority ribotypes constituting less than $30 \%$ of a mixture would not likely be detected, leading to underestimates of the frequency of multiple infections in host individuals.
\end{abstract}

Keywords: Osedax, 165 rRNA, Ribotyping, Oceanospirillales, Endosymbionts

\section{Background}

Most of the benthic marine environment, which covers nearly $70 \%$ of Earth, lacks sufficient sunlight to support photosynthesis. Although food supplies in this vast aphotic zone derive primarily from marine snow (organic detritus produced in the photic zone), dense animal communities aggregate at sites of organic enrichment resulting from debris-falls such as rotten kelp, sunken wood, and the carcasses of large marine animals [1]. Similar "oases" occur at hydrothermal vents and hydrocarbon

\footnotetext{
* Correspondence: vrijen@mbari.org

'Monterey Bay Aquarium Research Institute, Moss Landing, CA 95039, USA Full list of author information is available at the end of the article
}

seeps, where geochemical processes (e.g. methane and sulfide gases) support chemosynthetic microbes. Microbes also serve as epi- and endosymbionts that provide nutrition to a wide diversity of invertebrate hosts [2]. For some taxa (e.g. vesicomyid clams), the symbionts are transmitted vertically, which provides "symbiont assurance" to animal larvae that colonize newly formed habitat, but for most taxa, symbionts are acquired locally from environments in which their larvae or juveniles settle. Modes of symbiont transmission have profound consequences for evolutionary and ecological processes affecting the participants in these symbioses [3].

The siboglinid tubeworms commonly found at vents, seeps and debris-falls acquire their endosymbionts 
environmentally [4]. Lacking mouths and digestive tracts, the adult worms rely on bacteria that live in specialized cells (bacteriocytes) concentrated in various tissue layers [5]. The family Siboglinidae encompasses four evolutionary lineages [6-8]. Vestimentiferans, monoliferans and frenulates host chemoautotrophic endosymbionts $[9,10]$, whereas the bone-eating Osedax worms (Figure 1) host heterotrophic bacteria [11].

Osedax develop proliferative "roots" that penetrate sunken bones to extract organic compounds [8]. Five Osedax species have been named since the recent discovery of this genus [8,12-14]: O. rubiplumus (2004), O. frankpressi (2004), and O. roseus (2008) from Monterey Bay, California; O. mucofloris (2005) from the Kosterfjord, Sweden; and O. japonicus (2006) from Cape Nomamisaki, Japan. Twelve additional species found in the Monterey Bay were assigned morphologically descriptive "placeholder" names while they await formal descriptions [15]. Mitochondrial cytochrome-c-oxidase subunit-1 (COI) sequences provide convenient DNA-barcodes for these 17
Osedax species (Table 1 in reference [15]). Minimal COI divergence between them is $8.4 \%$, an order-of-magnitude greater than the maximal divergence within a species (0.82\%). Concordant differences exist for mitochondrial 16S rRNA and nuclear genes encoding 18S rRNA, 28S rRNA and Histone-3. Comparisons with the published DNA sequences revealed additional undescribed species from the eastern and western Pacific and the Antarctic oceans (A. Glover, personal communication).

Ribotyping (16S rRNA sequencing) studies identified a diverse assemblage of primary and secondary microbes associated with Osedax and the sediments surrounding whale bones [11,12,16-18]. The primary endosymbionts, Gammaproteobacteria related to Neptunomonas and belonging to the order Oceanospirillales, live in bacteriocytes located in the interior tissue that surrounds the ovisac and proliferative roots [5,13,16,19]. Osedax eggs and pre-settling larvae are aposymbiotic [20]. They acquire the primary endosymbionts following settlement, but the mechanism and timing of infections remain
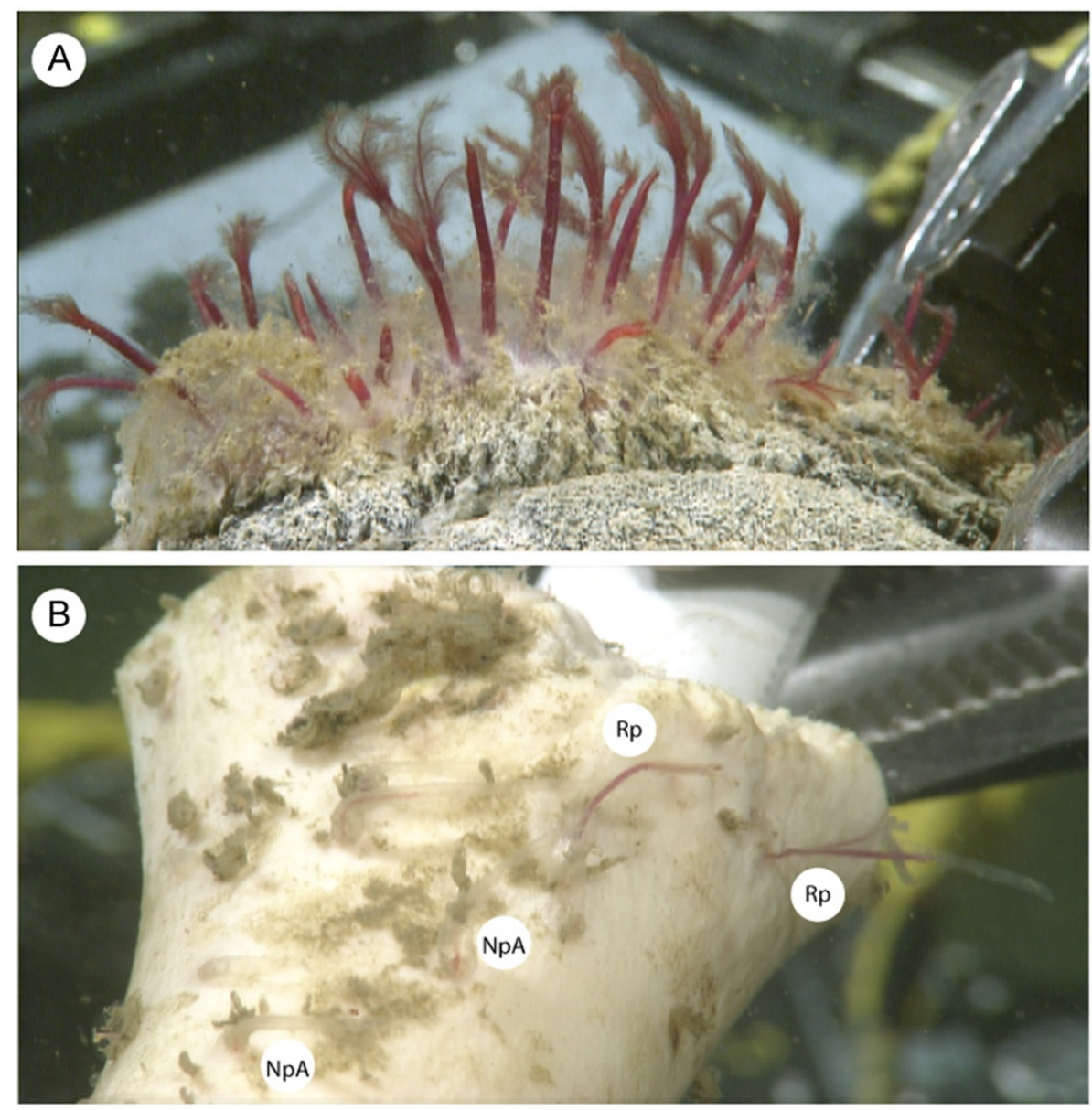

Figure 1 In situ photographs of Osedax on whale (A) and cow (B) bones sampled from the 1820-m locality. Scales are similar as determined from the manipulator claw. The porous whale bone has a high density of worms composed mostly of $O$. rubiplumus. In contrast, $O$. rubiplumus and $O$. nude-palp A sparsely populated the hard surface of the cow bone. 
Table 1 Submersible expeditions to recover Osedax samples

\begin{tabular}{llrrr}
\hline & & \multicolumn{2}{c}{ Number Osedax examined } \\
\hline Date & Dive no.* & Days $^{\dagger}$ & Whale bone & Cow bone \\
20-Mar-06 & & 0 & deployed & \\
23-May-06 & T990 & 64 & 9 & deployed \\
24-Oct-06 & T1048 & 218 & 24 & 9 \\
10-Jan-07 & T1071 & 296 & 21 & 0 \\
15-Aug-07 & T1119 & 513 & 22 & 14 \\
18-Dec-07 & T1163 & 638 & 20 & 14 \\
10-Mar-09 & DR12 & 1086 & 27 & 6 \\
\hline
\end{tabular}

* ROV Tiburon dives preceded by "T"; and ROV Doc Ricketts dives preceded by "DR".

${ }^{+}$Days since deployment of whale- 1820 carcass.

unclear $[5,18]$. The aposymbiotic larvae of another siboglinid tubeworm, Riftia pachyptila, are infected transdermally by thiotrophic bacteria during a narrow window of development that precedes metamorphosis to a juvenile stage [21]. Osedax, on the other hand, are hypothesized to acquire endosymbionts repeatedly as individual roots proliferate through sunken bones [18]; consequently, multiple ribotypes can occur within individual bacteriocytes, and frequencies of the ribotypes may vary among the lobules of a worm's ovisac and root system. Juvenile and adult stages of $O$. frankpressi collected several months apart from the same whale carcass hosted different symbiont strains [16]. Compared with vestimentiferans, the primary endosymbionts associated with Osedax are more dynamic and diverse.

To assess the temporal dynamics of endosymbiont diversity in Osedax, we conducted a three-year time series analysis of Oceanospirillales bacteria from an experimental whale-fall deployed during March 2006 at $1820 \mathrm{~m}$ depth in Monterey Bay, California. Cow bones were also deployed at the site, and samples were obtained with robotic submarines six times during this three-year period (Table 1). Osedax species sampled from whale and cow bones were identified by their unique $\mathrm{COI}$ barcodes [15]. The associated bacteria were characterized by ribotyping, which was facilitated by employing PCR primers specifically designed to amplify the $16 S$ rRNA sequences from these Oceanospirillales bacteria [22]. The sequence traces obtained with direct sequencing of PCR products tend to reveal only the majority targets in complex bacterial mixtures. To better assess within-host diversity of these bacterial strains, we examined clone-libraries generated from a subset of individuals. Furthermore we tested the reliability of standard PCR reactions in detecting multiple infections by examining dilution series constructed from mixed ribotypes. As essentially all individuals proved to be multiply infected, we also examined the potential for compartmentalization, i.e. physical separation of the different endosymbiont strains, among different anatomical parts of a host individual. Finally, we conducted two-way contingency tests to assess host-symbiont specificity and the impact of environmental factors on the distribution of symbiont ribotypes. Throughout this publication, we use the terms "ribotype" to denote bacterial strains marked by a distinct $16 S$ sequence and "ribospecies" to denote a grouping of ribotypes that share $\geq 97 \%$ sequence similarity sensu [23,24].

\section{Methods}

\section{Sample collection}

Bones colonized by Osedax (Figure 1) were sampled from the carcass of a juvenile gray whale deployed on 20 March 2006 at a depth of $1820 \mathrm{~m}$ in the Monterey Submarine Canyon, CA $\left(36.772^{\circ} \mathrm{N}\right.$ and $\left.122.083^{\circ} \mathrm{W}\right)$. Subsequent monitoring of the whale-fall community at this site has been described $[25,26]$. Cow bones were deployed on 23 May 2006 approximately $10 \mathrm{~m}$ away from the whale carcass [27]. We obtained the present samples during six R/V Western Flyer expeditions (Table 1) that employed the remotely operated vehicles (ROVs) Tiburon and Doc Ricketts operated by the Monterey Bay Aquarium Research Institute (MBARI). Whale bones were recovered during all six expeditions and cow bones were recovered during expeditions 2-6. All bones were sampled with robotic manipulators and placed in seawaterfilled containers that were closed to maintain near-bottom temperatures $\left(\right.$ mean $\left.=2.3^{\circ} \mathrm{C}\right)$ during the ascent. A sediment sample was taken with a $9 \mathrm{~cm}$-wide push-core next to a whale bone sampled during dive T1163. At the surface, the bones were stored in cold filtered seawater $\left(4^{\circ} \mathrm{C}\right)$ before removal of the embedded Osedax worms. Individual worms were stored in separate cryovials containing 95\% ethanol or frozen at $-80^{\circ} \mathrm{C}$.

We examined 162 Osedax worms for the present analyses. Root, trunk and palp tissues (Figure 2) were dissected from each individual, if possible, and stored separately for subsequent analyses. To test for possible compartmentalization of the symbiont infections within host individuals (i.e. physical separation of multiple infections), we dissected basal trunk tissue, anterior ovisac, posterior ovisac/root, outer ovisac sheath, and inner ovisac tissues from 21 of the larger specimens (7 worms from dive T1119, and 14 worms from dive DR12). Separate lobes of ovisac tissues were examined individually from several of the larger worms.

\section{General phylogenetic and statistical methods}

Sequence alignments were conducted with CLUSTALX 2.0.12 [28], and edited in MACCLADE 4.08 [29]. Analysis of DNA sequence diversity was conducted with MEGA5 [30]. Appropriate DNA substitution models 


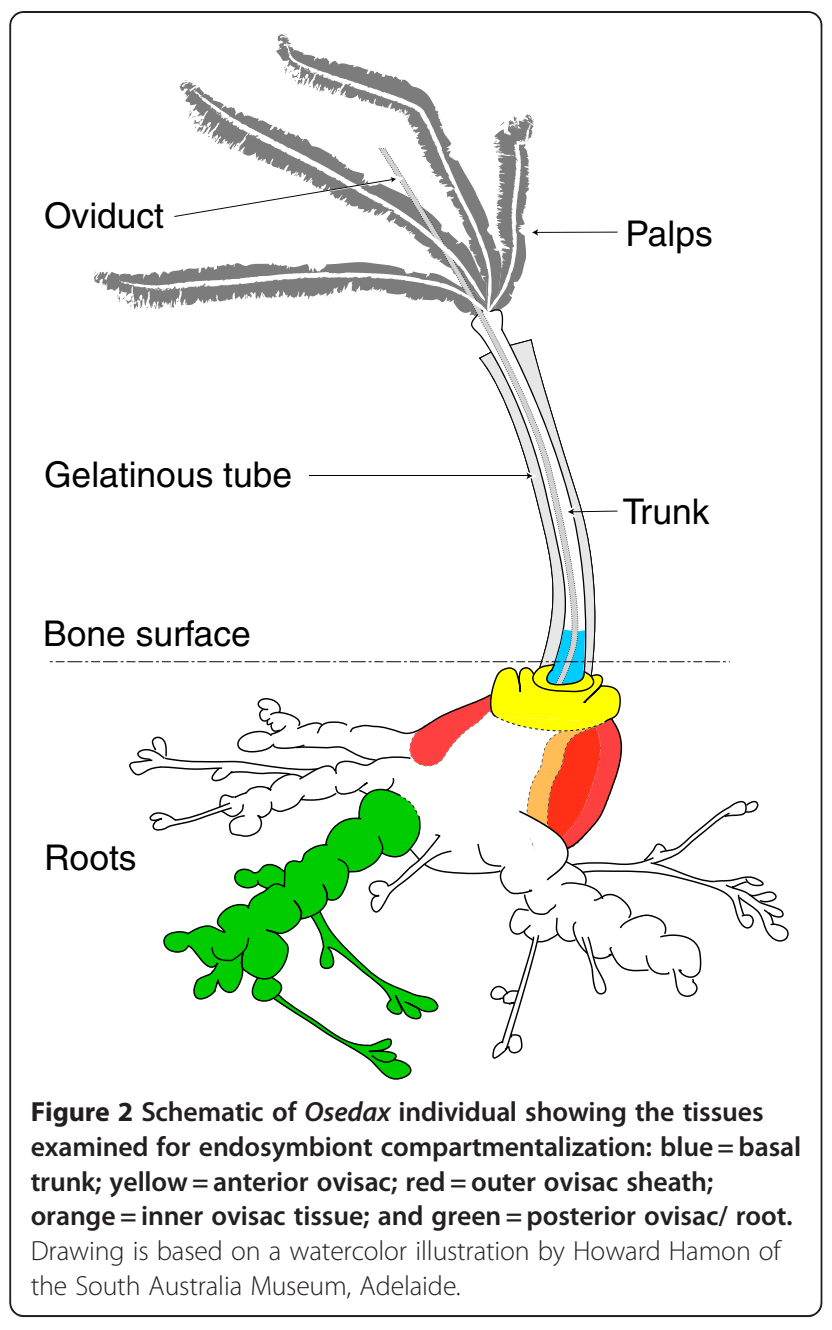

were determined with JMODELTEST v. 1.0.1 [31,32]. The model with the lowest Bayesian Information Criterion (BIC score) was chosen for phylogenetic analyses conducted with MR. BAYES v. 3.1.3 [33,34]. Each analysis was conducted as six chains for $5.1 \times 10^{6}$ generations. Print and sample frequencies were 1000 generations, and the burn-in was the first 100 samples. Analyses were repeated five times and the resulting data were visualized using TRACER v. 1.3 [35] to determine the appropriate burn-in period and ensure data had reached convergence. Trees were visualized using FIGTREE v. 1.3.1 [36]. A parsimony network of $16 \mathrm{~S}$ sequences was constructed with the program TCS v. 1.18 [37]. Two-way contingency tests of independence between endosymbiont ribospecies, host species, time of sampling, and type of bone were conducted with JMP v. 7.02 software [38].

\section{Analysis of host $\mathrm{CO}$ sequences}

Osedax individuals were identified by their unique $C O I$ barcodes following previously described procedures [15].
Briefly, we used the DNeasy kit (Qiagen, Valencia, CA) to extract DNA. PCR was conducted with AmpliTaq Gold (Applied Biosystems Inc., Foster City, CA, USA) and $\mathrm{COI}$ primers developed for siboglinid worms [39] to amplify approximately $1200 \mathrm{bp}$ of sequence. PCR parameters were as follows: initial denaturation at $95^{\circ} \mathrm{C} /$ $10 \mathrm{~min}, 35$ cycles $\left(94^{\circ} \mathrm{C} / 1 \mathrm{~min}, 55^{\circ} \mathrm{C} / 1 \mathrm{~min}\right.$, and $72^{\circ} \mathrm{C} /$ $1 \mathrm{~min}$ ), and final extension at $72^{\circ} \mathrm{C} / 7 \mathrm{~min}$. $\mathrm{COI}$ amplicons were diluted in $50 \mu \mathrm{l}$ sterile $\mathrm{H}_{2} \mathrm{O}$ and cleaned with Multiscreen HTS PCR 96 filter plates (Millipore Corp., Billerica, MA, USA). Sequencing reactions were conducted with the same primers, and the resulting sequences were analyzed bidirectionally on an ABI 3100 using BigDye terminator v.3.1 chemistry (Applied Biosystems Inc., Foster City, CA, USA). Osedax sequences new to this study were deposited in GenBank (acc. nos. JX280608 - 613) and compared with published sequences [GenBank acc. nos. in references: 8, 12, 13, $15,25]$.

\section{Analysis of symbiont $16 \mathrm{~S}$ sequences}

New 16S sequences were obtained with primers specifically designed to amplify a $672 \mathrm{bp}$ fragment from Oceanospirillales bacteria associated with Osedax [22]: $435 \mathrm{~F}$ : 5'-CAGCWGTGAGGAAAGGTT-3', and 1213R: 5'TGTGTAGCCCAACTCG-3'. PCR was conducted with HotStartTaq (Qiagen, Valencia, CA) according to the following parameters: initial denaturation at $95^{\circ} \mathrm{C} / 10 \mathrm{~min}$, 30 cycles $\left(94^{\circ} \mathrm{C} / 1 \mathrm{~min}, 54^{\circ} \mathrm{C} / 1 \mathrm{~min}\right.$, and $\left.72^{\circ} \mathrm{C} / 1 \mathrm{~min}\right)$, and final extension at $72^{\circ} \mathrm{C} / 10 \mathrm{~min}$. If initial concentrations of target DNA were small, we added two to five PCR cycles. Purification and sequencing of amplicons were conducted as before with COI. PCR reactions were repeated in cases when chromatograms of the sequence traces appeared to involve mixed infections by multiple symbiont strains, and to verify singletons, i.e. ribotypes found only once in this study. Due to sequence ambiguities in close proximity of the forward and reverse primers, the sequences were trimmed at these ends and final segments of $672 \mathrm{bp}$ length used for the analysis. Oceanospirillales sequences new to this study were deposited in GenBank (acc. nos. JX280614-661) and compared with published ribotypes [GenBank acc. nos. in Figure 3; references: 13, 16-18].

\section{Assessing mixed infections}

Sequence traces were used to designate individual worms as multiply infected if the secondary peak at a polymorphic nucleotide site was at least half of the height of the primary peak. We did not consider lesser peaks, as they were confounded with background variation. Potentially mixed sequence traces were verified by re-amplification and sequencing. We resolved the phases of mixed symbiont ribotypes in the following ways. 


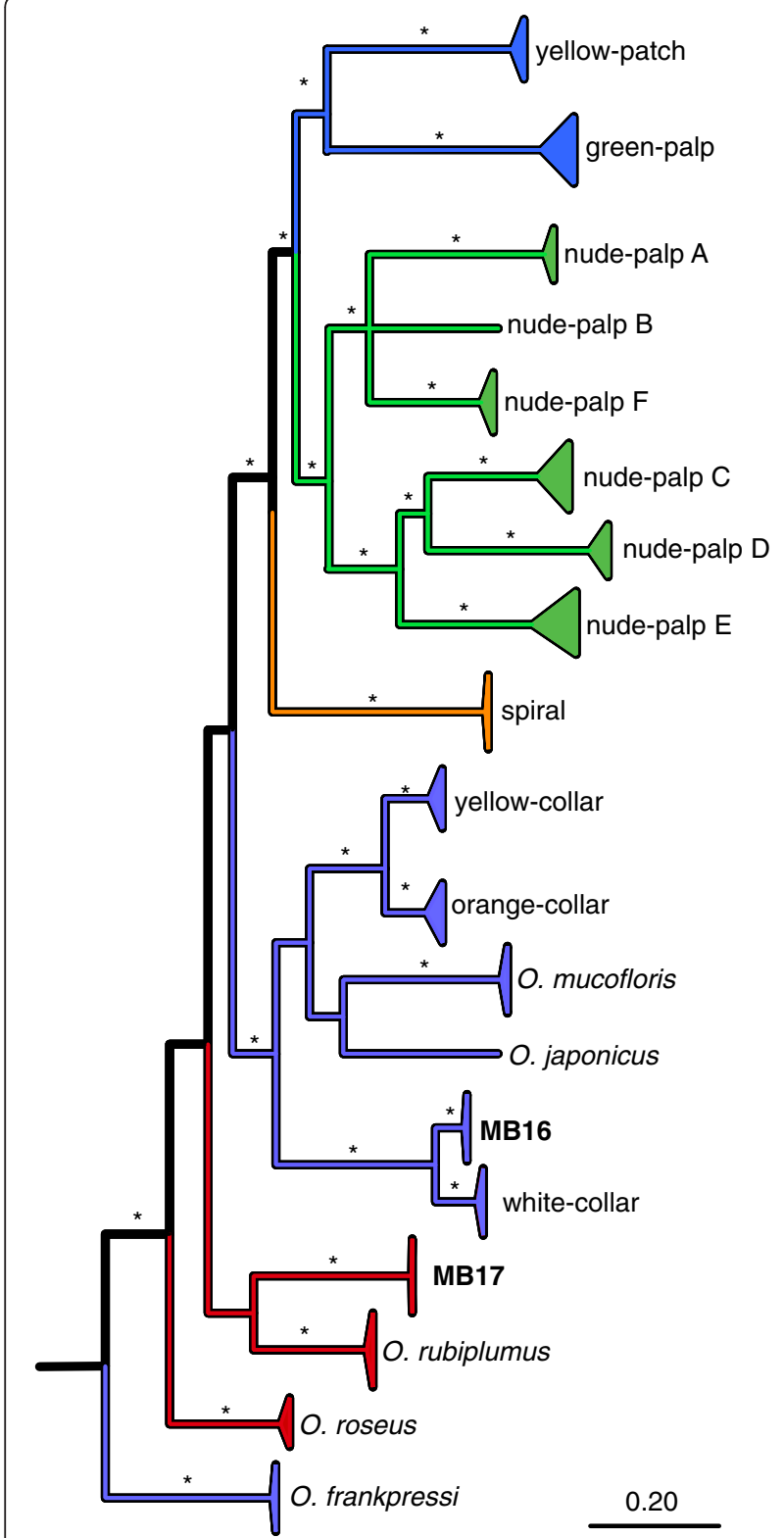

Figure 3 Bayesian phylogenetic relationships of mitochondrial $\mathrm{COI}$ in 19 Operational Taxonomic Units (OTUs) of Osedax boneworms. Two OTUs are new to this study (MB16 and MB17). The triangles represent the maximum depth of the presently known sequence diversity in each OTU. Asterisks $\left(^{*}\right)$ on nodes and branches represent Bayesian posterior probability (BPP) values $\geq 0.99$. Branches are colored to be consistent with previously published groupings [15]

Mixtures involving ambiguities at single nucleotide positions (e.g., $\mathrm{Y}=\mathrm{T}$ or $\mathrm{C}$ at position 663) could be manually decomposed into alternative ribotypes. If ambiguities occurred at multiple positions (e.g., $\mathrm{R}=\mathrm{A}$ or $\mathrm{G}$ at position 366 and $Y$ at position 663), we inferred phases of the constituent ribotypes by generating clone libraries with the Invitrogen Topo TA cloning kit (Invitrogen,
Carlsbad, CA). Singleton ribotypes in the libraries that were not repeated were treated as cloning artifacts and excluded from subsequent analyses, as were the remaining unresolved ambiguities.

Dilution series were used to determine whether PCR "dropouts" of minority ribotypes due to low quantities of target DNA occurred in mixed infections. Various ratios (e.g., 0:100, 10:90. 20:80, . . 100:0) were generated from two pairs of cloned $16 S$ amplicons, and one pair of uncloned samples that differed at one or more nucleotide positions. Each dilution series was replicated three times. PCR reactions were conducted with the known mixtures, and amplicons were sequenced as previously described.

\section{Results}

Host diversity

Based on previously published COI sequences [15], two host taxa, MB16 and MB17, were new to this study (Figure 3). Osedax MB16 is related to white-collar (sequence divergence, $D=7.4 \%$ ), whereas Osedax MB17's is most closely related to O. rubiplumus $(D=20.3 \%)$. Altogether, the present sample of 162 Osedax worms contained nine host species in the following order of abundance: O. rubiplumus $(n=76)$, O. frankpressi $(n=34)$, green-palp $(n=14)$, nude-palp A $(n=12)$, nude-palp D $(n=6)$, O. roseus $(n=3), \operatorname{MB} 17(n=3)$, MB16 $(n=2)$; nude-palp C $(n=1)$. Eleven very small worms did not provide reliable $C O I$ sequences after repeated attempts and remained unidentified. For subsequent statistical analyses, they were nested in the category "other" (Table 1).

\section{Symbiont diversity}

The symbiont-specific primers amplified 48 distinct $16 \mathrm{~S}$ ribotypes in the present samples (GenBank acc. nos. JX280614-661). Thirty-two ribotypes were revealed with PCR and direct sequencing from symbiont-bearing tissues, and 16 were revealed in clone libraries. These 672bp $16 S$ sequences exhibited 149 polymorphic sites $(S)$. The mean number of nucleotide substitutions between pairs of ribotypes was 33.8 . For these 48 ribotypes, the mean nucleotide diversity per site $(\pi)$ was 0.05021 and the normalized diversity $\left(\theta_{\mathrm{S}}\right)$ was 0.05214 per site.

We conducted a Bayesian phylogenetic analysis of the 48 new ribotypes (highlighted in yellow, Figure 4) in conjunction with previously published $16 S$ sequences, mostly from whale-fall samples. Symbiont ribotypes that differed by $\leq 3 \%$ were clustered into seven distinct ribospecies (Rs1-Rs7, Table 2) that were clearly distinguished as well-supported clades in the Bayesian tree (Posterior Probabilities 20.99 ). Ribospecies Rs3-Rs7 were not found among the present samples from the $1820-\mathrm{m}$ locality. Rs4 and Rs5 were previously identified from shallower whale-falls (383 m) in Monterey Bay and Sweden, 


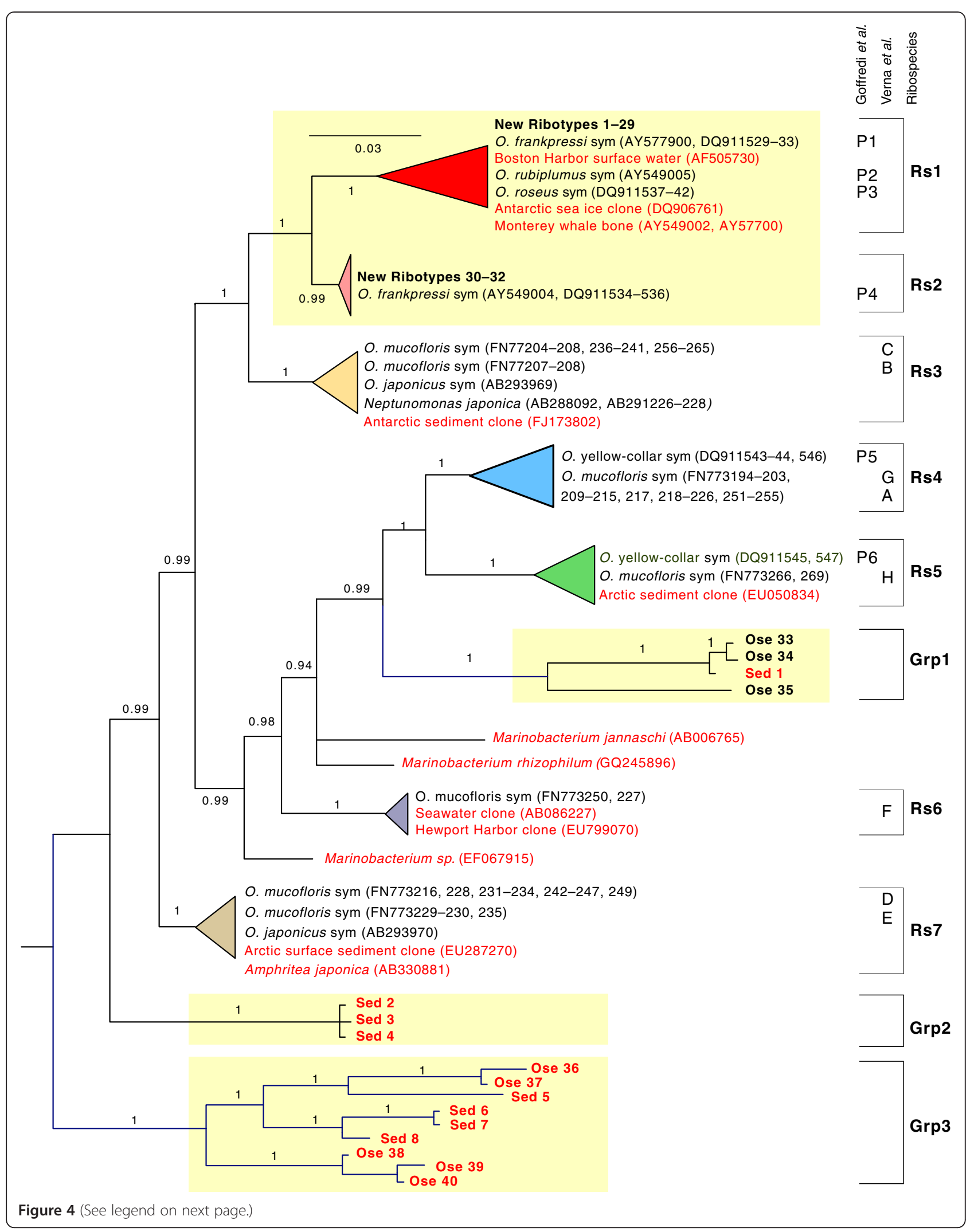


(See figure on previous page.)

Figure 4 Bayesian phylogenetic analysis of ribotype sequences from Oceanospirillales bacteria associated with Osedax bone worms (black font) and environmental samples (red font). The yellow highlighted branches include sequences that are new to this study. Closely related endosymbiont ribotypes with genetic distances $\leq 3 \%$ were assembled into triangles and designated as ribospecies Rs $1-R s 7$. For reference, the phylotype designations of Goffredi et al. [11] (P1-P6) and Verna et al. [18] (A-H) are nested within the new ribospecies designations.

Groupings of recovered ribotypes that did not cluster with endosymbiont lineages are indicated as Grp1-Grp3). The numbers along branches represent Bayesian posterior probability distributions (PPDs). The branches with PPDs $<0.94$ were collapsed into polytomies (e.g., M. jannaschi and M. rhizophilum).

and Rs3, Rs6 and Rs7 were previously identified from shallow whale-falls off Sweden (25-125 m) and Japan ( $\sim 200 \mathrm{~m})$. Thirty-two of the new ribotypes obtained with PCR and direct sequencing from Osedax tissues fell into ribospecies Rs1 and Rs2. Sixteen of the new ribotypes were identified in clone libraries derived from Osedax tissues (Ose 33-40) and a sediment sample (Sed 1-8). They were distributed in three regions of the tree and were not related to the primary Osedax endosymbionts. Because the tree is unrooted, we cannot infer ancestral states.

\section{Host, substrate and temporal components of symbiont diversity and abundance}

The 32 ribotypes obtained by direct sequencing from the Osedax tissues fell into ribospecies Rs1 (ribotypes 1-29) and Rs2 (ribotypes 30-32), which differed minimally by 13 nucleotide substitutions with a mean sequence divergence of $3.52 \%$. A statistical parsimony network (Figure 5) clearly reveals that Rs1 was more diverse and abundant in the present samples. Half of the Rs1 ribotypes (52\%) were singletons that were verified with second PCRs from the original tissue extracts. One of the three Rs2 ribotypes was a singleton.

Frequencies of Rs1 and Rs2 shifted during this timeseries (Figure 5A). A two-way contingency test of ribospecies frequencies against sample dates revealed a highly significant association (Table 3A). Rs1 was overrepresented in the early samples through Dec-07 and Rs2 was significantly overrepresented in the Mar-09 sample. Frequencies of the Osedax host species also changed significantly during this period (Table 3C). O. Rubiplumus was overrepresented in the first two samples and it became increasingly scarce after Aug-07. O. frankpressi was not abundant until Aug-07. O. green-palp and O. nude-palpA were only abundant in the Dec-07 sample. The remaining five species were rare and lumped into the category "other" to avoid possible statistical artifacts due to "sampling zeros" [40]. Although the hosts and endosymbionts both varied significantly with time, they exhibited no association with one another (Figure 5B; Table 3D). Rs2 clearly dominated in all the host species. Frequencies of the two ribospecies were independent of whale or cow bone substrates (Table 3B), but frequencies of the host species were associated with the type of bone (Table 3E). O. rubiplumus and O frankpressi densely populated whale bones, but they were rare on the cow bones (Figure 1). These larger worms may have obscured the presence of small and relatively transparent species, such as $O$. green-palp and $O$. nude-palp- $A$, on the densely populated whale bones. The smaller worms were more readily observed and sampled from the sparsely populated cow bones (Figure 1B).

\section{Assessing multiple symbiont infections}

PCR and direct sequencing occasionally produced ambiguous sequence traces that suggested mixed symbiont infections within individual worms. To verify the presence

Table 2 Sequence divergence within (bold italics, on diagonal) and between (lower triangle) major bacterial clades illustrated in the Bayesian phylogenetic analysis (Figure 4)

\begin{tabular}{|c|c|c|c|c|c|c|c|c|c|c|}
\hline & Rs1 & Rs2 & Rs3 & Rs4 & Rs5 & Rs6 & Rs7 & Grp2 & Grp1 & Grp3 \\
\hline Rs1 & 0.0102 & & & & & & & & & \\
\hline Rs2 & 0.0352 & 0.0020 & & & & & & & & \\
\hline Rs3 & 0.0729 & 0.0512 & 0.0031 & & & & & & & \\
\hline Rs4 & 0.1203 & 0.0862 & 0.0892 & 0.0182 & & & & & & \\
\hline Rs5 & 0.1377 & 0.1206 & 0.0947 & 0.0737 & 0.0158 & & & & & \\
\hline Rs6 & 0.1153 & 0.0804 & 0.0679 & 0.0869 & 0.1119 & $n / c$ & & & & \\
\hline Rs7 & 0.0764 & 0.0681 & 0.0542 & 0.1025 & 0.1046 & 0.0635 & 0.0095 & & & \\
\hline Grp2 & 0.1590 & 0.1493 & 0.1561 & 0.1668 & 0.1788 & 0.1621 & 0.1117 & 0.0010 & & \\
\hline Grp1 & 0.1901 & 0.1924 & 0.1779 & 0.1665 & 0.1689 & 0.1650 & 0.1862 & 0.2136 & 0.0630 & \\
\hline Grp3 & 0.2220 & 0.2070 & 0.2011 & 0.2167 & 0.2007 & 0.2273 & 0.1927 & 0.2301 & 0.2663 & 0.1090 \\
\hline
\end{tabular}


A

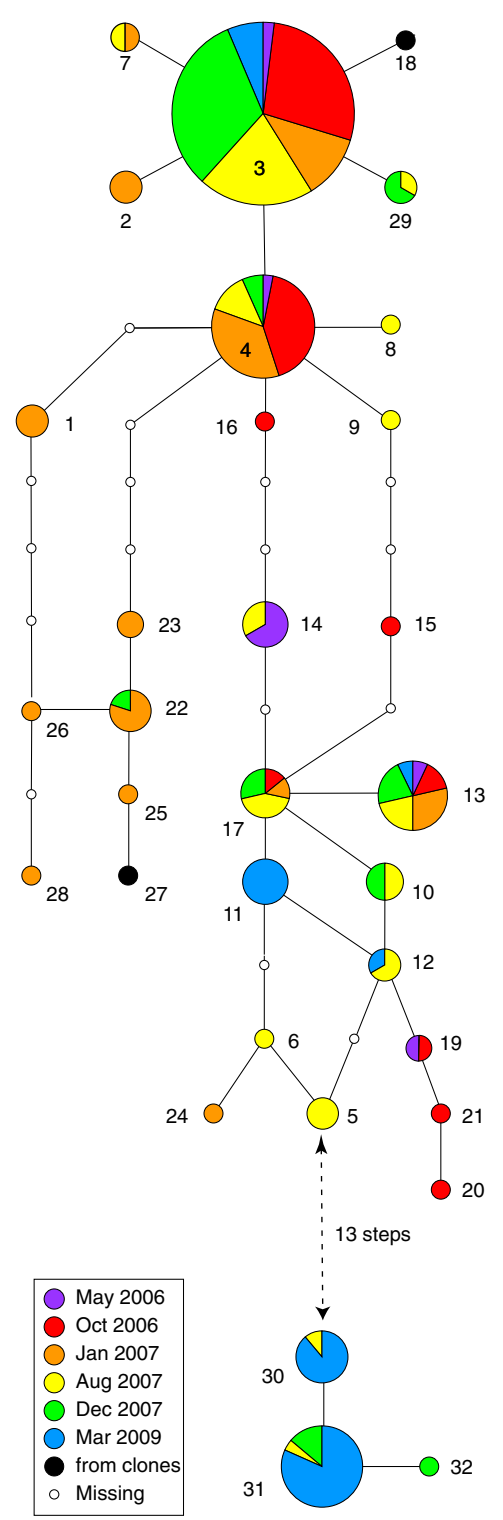

B

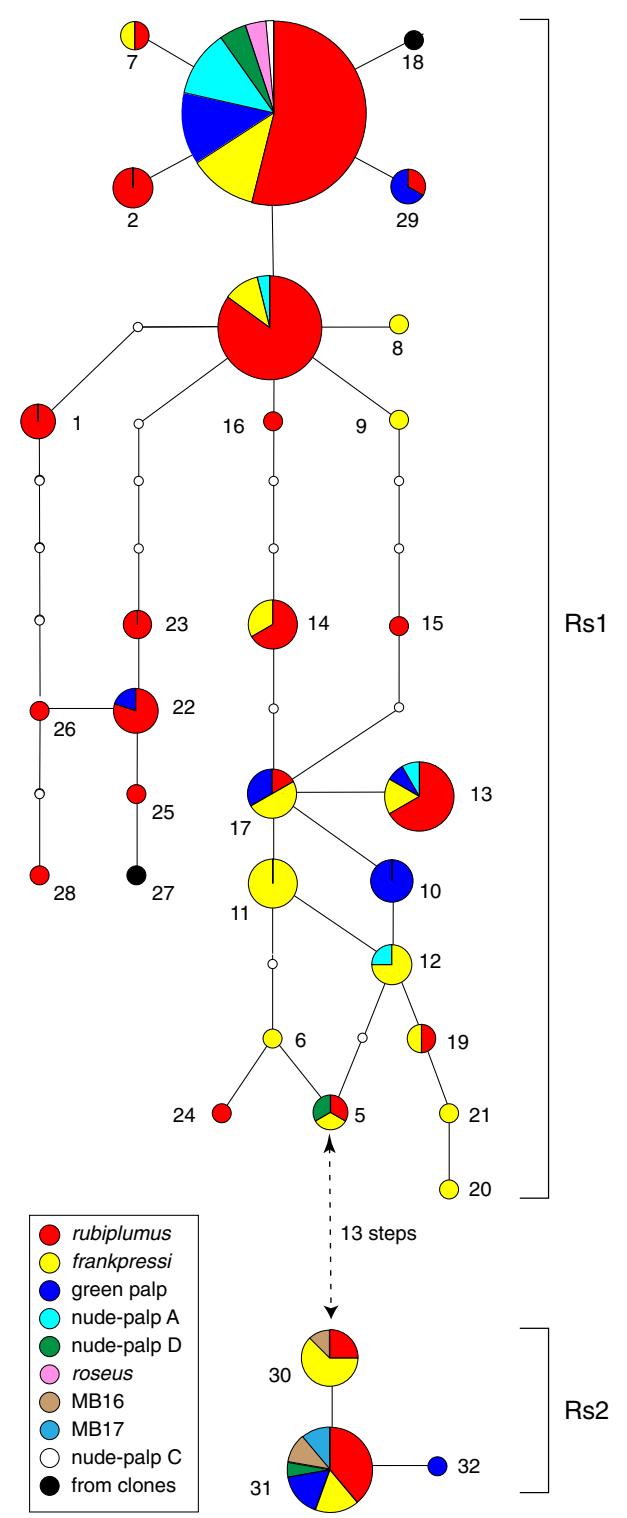

Figure 5 Parsimony networks for endosymbiont ribotypes 1-32: A. Colored pie-slices indicate the proportion of ribotypes assigned to: (A) sample periods; and (B) host species (unidentified hosts excluded). Sizes of the pies scaled to reflect ribotype frequencies. Connecting lines indicate a single mutational step. Empty dots indicate inferred ribotypes that were not sampled in this study.

of mixtures, we generated clone libraries from a subsample of 15 worms. Depending on the diversity observed, 12 to 47 clones were examined from each worm. Each of the 15 worms exhibited mixed infections involving at least two to nine distinct ribotypes. Although PCR and direct sequencing never identified a worm that simultaneously hosted ribospecies Rs1 and Rs2, the clone libraries identified one worm from a cow bone sample (T1163.cb1) that had both.

To determine the detection limits for multiple infections with PCR and direct sequencing, we generated dilution series involving mixtures of pure ribotypes from cloned Rs1 sequences and from mixtures involving different worms that hosted the Rs1 (worm F) and Rs2 (worm E) ribospecies (Table 4). Limits of detection were affected by the position of single nucleotide polymorphisms (SNPs) along the length of the $672 \mathrm{bp}$ amplicons. Based on this procedure we determined that minority ribotypes constituting less than $30 \%$ of the sequences in a mixture would not likely be detected by standard PCR.

\section{Symbiont compartmentalization}

To assess whether the different constituents of multiple infections were physically separated among various body 
Table 3 Two-way contingency tests involving symbiont ribospecies, host species, bone substrates and dive dates

A. Symbiont ribospecies by date

\begin{tabular}{|c|c|c|c|c|c|}
\hline Date & \multicolumn{2}{|c|}{ Rs1 } & \multicolumn{2}{|c|}{ Rs2 } & Total \\
\hline Oct-06 & 31 & 27.0 & 1 & 5.0 & 32 \\
\hline Jan-07 & 18 & 16.0 & 1 & 3.0 & 19 \\
\hline Aug-07 & 35 & 29.5 & 0 & 5.5 & 35 \\
\hline Dec-07 & 32 & 28.7 & 2 & 5.3 & 34 \\
\hline Mar-09 & 13 & 27.8 & 20 & 5.2 & 33 \\
\hline Total & 129 & & 24 & & 153 \\
\hline
\end{tabular}

$G=56.736 ; d f=5 ; P<0.0001^{*}$

B. Symbiont ribospecies by bone type

\begin{tabular}{rrrrrrr} 
Bone & \multicolumn{3}{c}{ Rs1 } & & Rs2 & Total \\
Whale & 94 & 93.6 & 17 & 17.4 & 111 \\
Cow & 35 & 35.4 & 7 & 6.6 & 42 \\
Total & 129 & & 24 & & 153 \\
& $G=0.042 ; d f=1 ; P=0.838$
\end{tabular}

\section{Host species by date}

\begin{tabular}{rcrcr} 
Date & \multicolumn{2}{c}{ rubiplumus } & \multicolumn{2}{c}{ frankpressi } \\
Oct-06 & 22 & 14.0 & 1 & 7.1 \\
Jan-07 & 19 & 8.3 & 0 & 4.2 \\
Aug-07 & 10 & 15.3 & 14 & 7.8 \\
Dec-07 & 9 & 14.9 & 0 & 7.6 \\
Mar-09 & 7 & 14.5 & 19 & 7.3 \\
Total & 67 & & 34 & \\
& $G=140.298 ; d f=16 ; P<0.0001$
\end{tabular}

\begin{tabular}{rrrrrrr}
\multicolumn{2}{c}{ green-palp } & \multicolumn{2}{c}{ nude-palp A } & \multicolumn{2}{c}{ other } & Total \\
1 & 2.7 & 0 & 2.5 & 8 & 5.6 & 32 \\
0 & 1.6 & 0 & 1.5 & 0 & 3.4 & 19 \\
0 & 3.0 & 2 & 2.7 & 9 & 6.2 & 35 \\
12 & 2.9 & 10 & 2.7 & 3 & 6.0 & 34 \\
0 & 2.8 & 0 & 2.6 & 7 & 5.8 & 33 \\
13 & & 12 & & 27 & & 153
\end{tabular}

D. Host species by symbiont ribospecies

\begin{tabular}{|c|c|c|c|c|c|c|c|c|c|c|c|}
\hline \multirow{2}{*}{$\begin{array}{r}\text { Ribo-species } \\
\text { Rs1 }\end{array}$} & \multicolumn{2}{|c|}{ rubiplumus } & \multicolumn{2}{|c|}{ frankpressi } & \multicolumn{2}{|c|}{ green-palp } & \multicolumn{2}{|c|}{ nude-palp A } & \multicolumn{2}{|c|}{ other } & Total \\
\hline & 8 & 10.5 & 7 & 5.3 & 2 & 2.0 & 1 & 1.9 & 6 & 4.2 & \\
\hline Rs2 & 59 & 56.5 & 27 & 28.7 & 11 & 11.0 & 11 & 10.1 & 21 & 22.8 & \\
\hline \multirow[t]{2}{*}{ Total } & \multicolumn{2}{|l|}{67} & \multicolumn{2}{|l|}{34} & \multicolumn{2}{|l|}{13} & \multicolumn{2}{|l|}{12} & \multicolumn{2}{|l|}{27} & \\
\hline & \multicolumn{10}{|c|}{$G=2.702 ; d f=4 ; P<0.6088$} & \\
\hline \multicolumn{11}{|c|}{ E. Host species by bone type } & \\
\hline Bone & \multicolumn{2}{|c|}{ rubiplumus } & \multicolumn{2}{|c|}{ frankpressi } & \multicolumn{2}{|c|}{ green-palp } & \multicolumn{2}{|c|}{ nude-palp A } & \multicolumn{2}{|c|}{ other } & \\
\hline Whale & 63 & 48.6 & 32 & 24.7 & 0 & 9.4 & 10 & 8.7 & 6 & 19.6 & \\
\hline Cow & 4 & 18.4 & 2 & 9.3 & 13 & 3.6 & 2 & 3.3 & 21 & 7.4 & \\
\hline Total & 67 & & 34 & & 13 & & 12 & & 27 & & \\
\hline \multicolumn{11}{|c|}{$G=94.900 ; d f=4 ; P<0.0001$} & \\
\hline
\end{tabular}

${ }^{*} G=\log$ likelihood ratio; $d f=$ degrees of freedom; and $P=$ probability.

parts of host individuals, we examined tissue subsamples from 21 worms that were large enough to allow isolation of three or more distinct tissues (Table 5). $16 \mathrm{~S}$ sequences were amplified from all the tissue types examined. Three out of seven worms from dive T1119 and five out of 14 worms from dive DR12 generated symbiont sequences from green colored posterior trunk tissues. Several of the worms hosted multiple infections, e.g., worm T1119.2 hosted ribotypes Rs1.3 and Rs1.29, worm
T1119.4 hosted ribotypes Rs1.13 and Rs1.30, worm DR12.1.1 hosted Rs1.9 and Rs1.10, and worm DR12.1.10 hosted Rs1.11 and Rs1.12, which corresponds to $19 \%$ of infections involving multiple strains. Two host individuals (DR12.1.1 and T1119.2) exhibited signs of compartmentalization of different symbiont strains in ovisac sheath and inner ovisac tissues, and two other individuals (T1119.4 and DR12.1.10) simultaneously hosted two different ribotypes in their trunk tissues. 
Table 4 Detection of nucleotide composition at sites that are polymorphic in paired samples

\begin{tabular}{|c|c|c|c|c|c|c|c|c|c|c|c|c|c|}
\hline \multirow{2}{*}{ Mixture } & \multirow[b]{2}{*}{ Rep. } & \multirow{2}{*}{$\begin{array}{l}\text { Nucl. } \\
\text { position }\end{array}$} & \multicolumn{11}{|c|}{ Dilution ratio } \\
\hline & & & $0: 100$ & $10: 90$ & $20: 80$ & $30: 70$ & $40: 60$ & $50: 50$ & $60: 40$ & $70: 30$ & $80: 20$ & $90: 10$ & $100: 0$ \\
\hline \multirow[t]{3}{*}{$A \times B$} & 1 & 666 & C & C & C & $Y$ & $\mathrm{Y}$ & $\mathrm{Y}$ & $\mathrm{Y}$ & $\mathrm{T}$ & $\mathrm{T}$ & $\mathrm{T}$ & $\mathrm{T}$ \\
\hline & 2 & & C & C & C & $Y$ & $Y$ & $Y$ & $Y$ & $\mathrm{~T}$ & $\mathrm{~T}$ & $\mathrm{~T}$ & $\mathrm{~T}$ \\
\hline & 3 & & C & C & C & $\mathrm{Y}$ & $\mathrm{Y}$ & $\mathrm{Y}$ & $\mathrm{Y}$ & $\mathrm{T}$ & $\mathrm{T}$ & $\mathrm{T}$ & $\mathrm{T}$ \\
\hline \multirow[t]{3}{*}{$C \times D$} & 1 & 366 & A & A & $\mathbf{R}$ & $\mathbf{R}$ & $\mathbf{R}$ & $\mathbf{R}$ & $\mathbf{R}$ & G & G & G & G \\
\hline & 2 & & A & A & $\mathbf{R}$ & $\mathbf{R}$ & $\mathbf{R}$ & $\mathbf{R}$ & G & G & G & G & G \\
\hline & 3 & & A & $A$ & $\mathbf{R}$ & $\mathbf{R}$ & $\mathbf{R}$ & $\mathbf{R}$ & G & G & G & G & G \\
\hline \multirow[t]{9}{*}{$E \times F$} & 1 & 120 & $\mathrm{~T}$ & $\mathrm{~T}$ & $\mathrm{~T}$ & w & w & w & w & w & $A$ & A & A \\
\hline & 2 & & $\mathrm{~T}$ & $\mathrm{~T}$ & $\mathrm{~T}$ & w & w & w & w & w & A & A & A \\
\hline & 3 & & $\mathrm{~T}$ & $\mathrm{~T}$ & $\mathrm{~T}$ & w & W & w & W & w & A & A & $A$ \\
\hline & 1 & 363 & A & $A$ & $A$ & $\mathbf{R}$ & $\mathbf{R}$ & $\mathbf{R}$ & $\mathbf{R}$ & $\mathbf{R}$ & G & $\mathrm{G}$ & G \\
\hline & 2 & & $A$ & $A$ & $A$ & $\mathbf{R}$ & $\mathbf{R}$ & $\mathbf{R}$ & $\mathbf{R}$ & $\mathbf{R}$ & $\mathrm{G}$ & $\mathrm{G}$ & $\mathrm{G}$ \\
\hline & 3 & & A & $A$ & A & $\mathbf{R}$ & $\mathbf{R}$ & $\mathbf{R}$ & $\mathbf{R}$ & $\mathbf{R}$ & G & $\mathrm{G}$ & G \\
\hline & 1 & 660 & G & $\mathrm{G}$ & $\mathrm{G}$ & $G$ & $S$ & $S$ & $S$ & $S$ & $C$ & C & C \\
\hline & 2 & & $G$ & $G$ & $G$ & $G$ & $S$ & $S$ & $S$ & $S$ & C & C & C \\
\hline & 3 & & $G$ & $\mathrm{G}$ & $G$ & $G$ & $S$ & $S$ & $S$ & $S$ & C & C & C \\
\hline
\end{tabular}

Dilution series were created from mixtures of bacterial $16 \mathrm{~S}$ amplicons obtained from the following Osedax samples: (A) T1048.115 clone E6; (B) T1048.115 clone D11; (C) T1071.13 clone D4; (D) T1071.13 clone C6; (E) worm T1071.35; (F) worm T1048.110. Each mixture was replicated three times. Mixtures detected by sequencing software are marked in boldface.

\section{Discussion}

\section{Osedax hosts}

Nine Osedax lineages were sampled during this study, including three named species (O. rubiplumus, O. frankpressi, and $O$. roseus), four with placeholder names $(O$. green-palp, $O$. nude-palp A, $O$. nude-palp $\mathrm{D}$, and $O$. nude-palp C), and two (MB16 and MB17) reported here for the first time. Comparative analyses of $\mathrm{COI}$ sequences between the undescribed lineages and known Osedax species worldwide indicate that MB16 and MB17 deserve recognition as species. Ongoing studies involving a suite of nuclear and mitochondrial genes previously employed in Osedax systematics corroborate the distinct nature of MB16 and MB17 (S. Johnson, unpublished).

Osedax communities exhibit successional changes as bones decompose $[25,26]$. O. rubiplumus is an early colonizer that develops relatively shallow filamentous roots. It densely populated whale bones at the $2893-\mathrm{m}$ and $1820-\mathrm{m}$ Monterey whale-falls, and then was replaced by $O$. frankpressi, which produces a robust lobular root system that penetrates more deeply into bones. $O$. spiral, an unnamed species found at the $2893 \mathrm{~m}$ whale-fall, appeared even later and occupied bone fragments that were buried in sediments [15]. In the present study, $O$. rubiplumus and $O$. frankpressi exhibited a highly significant association with the time of sampling $(G=57.915$; $d f=4 ; P<0.00101)$. $O$. green-palp was disproportionally represented in the Dec-07 sample and rare at other times. The other host species were relatively infrequent throughout the study period, providing no foundation for assessing changes in their abundance.

The type of bone appears to affect frequencies of the host species (Figure 1). Whale bones deployed at the 2893-m and 1820-m localities were densely populated by $O$. rubiplumus and $O$. frankpressi, whereas cow bones, which have less porous surfaces (Figure 1B), were sparsely populated [27]. The smaller transparent species appeared to be more frequent on cow bones, but this may be due to the ease of seeing smaller worms when the larger species are scarce. Nonetheless, the bones of bovids do not naturally occur in marine environments, unless they are washed in during terrestrial floods or dumped as organic galley waste from passing ships [41]. Differences may exist among Osedax species in their natural utilization of bones from various vertebrate taxa, but a number of species can grow and reproduce on a range of bones including those from teleosts [22]. More recent experimental deployments of sea lion, elephant seal, turkey and sea turtle bones in Monterey Bay have also been colonized by one or more species of Osedax (Vrijenhoek, unpublished).

\section{Oceanospirillales endosymbionts}

The endosymbionts associated with these worms clustered into seven distinct clades (Rs1-Rs7) that we treat as ribospecies (Figure 4). The ribospecies concept has limitations for studies of microbial ecology and community structure, because it fails to consider functional genomic characteristics that might distinguish evolutionary 
Table 5 Ribotype amplifications from different host tissues of seven worms from Dive T1119 and 14 worms from Dive DR12

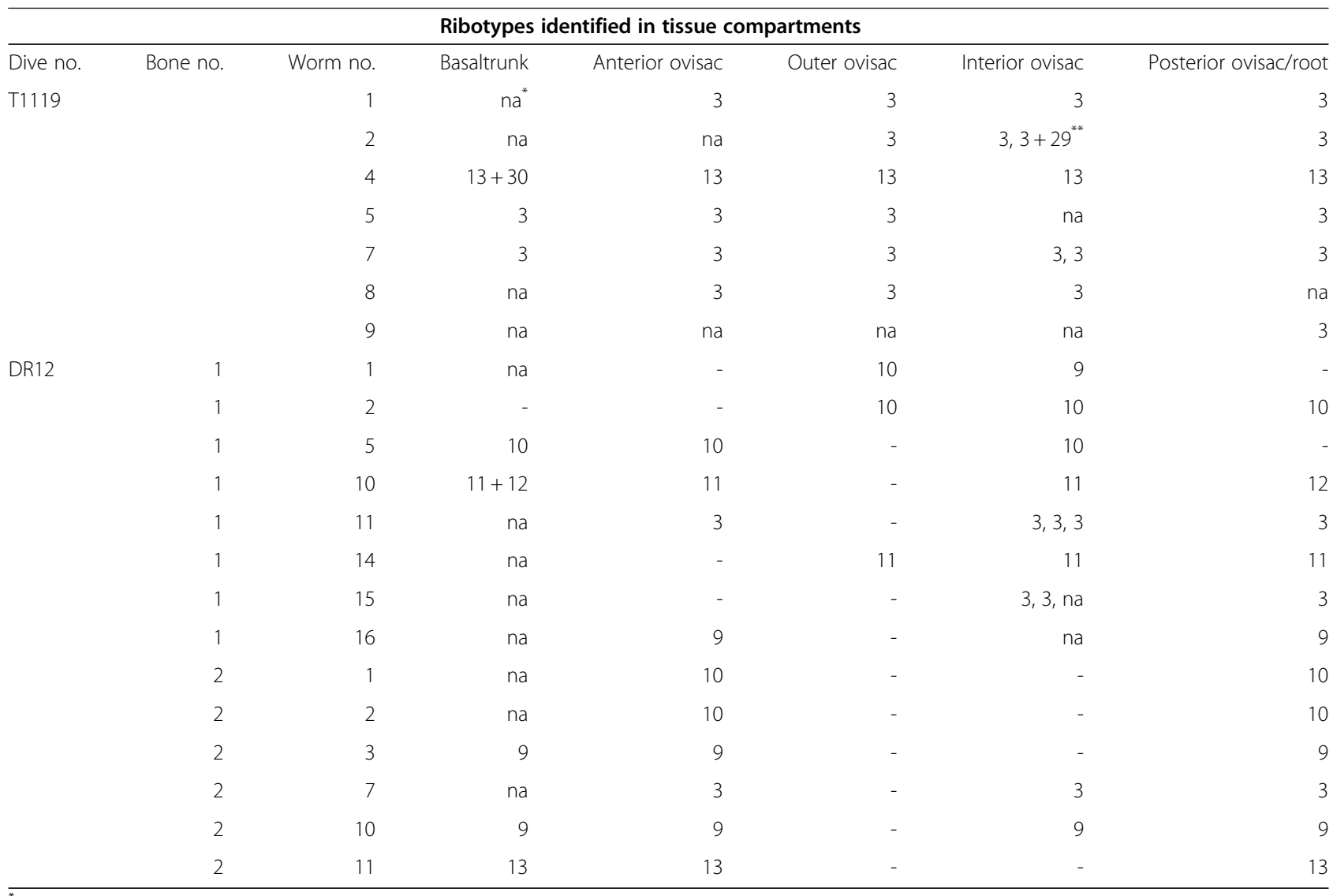

* na: no amplification from tissue, i.e. no signal for symbiont presence.

** The plus signs denote mixed ribotype infections. Commas separate ribotypes obtained from separate lobes of ovisac tissue.

${ }^{\dagger}$ dashes indicate tissues that were not available from a host individual.

lineages $[24,42,43]$. Nonetheless, it provides a useful method for reducing hierarchically lower-level molecular diversity into manageable clusters of related genotypes. Ribospecies Rs1 and Rs2 comprise a well-supported monophyletic assemblage that except for two environmental samples is restricted to deep waters. Rs1 and Rs2 were the primary endosymbionts in Osedax that grew on bones deployed at the 1820-m site. To date, we have not found these ribospecies at whale-falls shallower than $1000 \mathrm{~m}$ in Monterey Bay [16].

In contrast, ribospecies Rs3 through Rs7 comprise a paraphyletic assemblage that has only been reported from samples obtained at depths shallower than $500 \mathrm{~m}$. Rs3 should adopt the name Neptunomonas japonica for a free-living member cultured from whale-fall sediments off Kagashima, Japan [17]. Several of these shallow ribospecies have widespread distributions, and their paraphyletic assemblage is interspersed with free-living lineages including several Marinobacterium species, Sed1-8 ribotypes, and possibly the Ose33-40 ribotypes.
Although frequencies of ribospecies Rs1 and Rs2 varied independently of the Osedax host species, the endosymbiont population changed significantly with time. Goffredi et al. [16] first suggested that Osedax endosymbionts varied with time and the developmental stages of Osedax on whale bones. Similarly, an analysis of $O$. mucofloris endosymbionts from Minke whale carcasses found that time could explain about $31 \%$ of the variance in ribotype diversity of the endosymbionts, leading Verna et al. [18] to consider three hypotheses. From the present data, we can exclude their first hypothesis $(i)$ : "it was an artefact caused by the low number of individuals available for each sampling group." Our sample of host individuals was equitably represented across the entire time series (Table 1C). Furthermore, by grouping the 32 ribotypes into ribospecies Rs1 and Rs2, we avoided a potential statistical artifact due to sampling zeros, a consequence of small sample sizes [40]. Their second hypothesis seems plausible in the present case (ii): "the free-living population from which the endosymbionts 
were taken up varied over time, either randomly or because of environmental changes in the chemical and biological milieu at the whale-fall." The type of bone, whale or cow, did not affect ribospecies frequencies, but the endosymbionts are mostly located within the hosts' interior tissues and may not contact the bones directly. On the other hand, sediments surrounding the bones and supporting free-living infectious stages of these bacteria might play a role in this variation. Goffredi et al. [44] reported that ribotype composition of the archaeal community in sediments around the 2893-m Monterey whale-fall varied considerably in time with changes in methane and sulfide concentrations. A similar analysis of sediment samples for free-living components of the endosymbiont population is warranted. Verna et al.'s [18] third hypothesis seems less likely (iii): "choice of endosymbionts by host individuals varied over time either stochastically or because of specific selection processes driven by factors such as changes in the host's environment." Hypothesis iii requires the host to express a bacterial surveillance system that changes with time or conditions. If various host species with different morphologies, successional preferences, and potentially physiological characteristics do not appear to discriminate among the ribotypes of Rs1 and Rs2, it is difficult to imagine that any one species would exhibit changing "preferences" over time. For now, the simplest hypothesis is that acquisition of endosymbionts by Osedax is opportunistic, reflecting the changing composition of Oceanospirillales ribospecies in the local environment, but it is not random. Acquisition of the primary endosymbionts is clearly constrained to a subset of ribospecies that does not include the diverse paraphyletic assemblage of lineages found in the sediment sample (Sed1-8). Although related lineages (Ose33-40) were found in clone libraries from Osedax tissues, we suspect that these minority strains might be incidental infections that could not grow to high densities in the host's tissues. Alternatively, they might be incidental epibionts because the worms could not be cleanly separated from associated bone and sediment contamination. Further experiments involving fluorescence in situ hybridization (FISH) with strain-specific probes are required to test whether epibionts are involved.

\section{Mixed infections, tissue compartmentalization, and endosymbiont acquisition}

Mixed endosymbiont infections can segregate among different tissue compartments of individual O. mucofloris worms [18]. Direct sequencing of $16 S$ amplicons also revealed mixed sequence traces in a number of the Osedax individuals that we examined. $16 S$ clone libraries from a subset of worms revealed that each individual is likely to host multiple infections, with two to nine ribotypes per worm. Electron microscopy has revealed the presence of endosymbiont bacteria in root and ovisac tissues, within the lumen of multicellular glands associated with the trunk epidermis, but not the epidermis itself, where contact to bone material takes place [19]. We amplified and sequenced endosymbiotic ribotypes from root, different compartments of ovisac, and trunk (Figure 2, Table 5). Most of the worms (38.09\%) housed endosymbionts in root tissues; $88.24 \%$ housed them in the anterior ovisac; $90.00 \%$ in the outer ovisac; and $78.95 \%$ in the inner ovisac. Some trunk and ovisac tissues housed multiple endosymbiont strains, but root tissues typically housed a single dominant strain. Katz et al. [19] reported that root tissues contain intact and dividing (i.e. active) endosymbionts. Proliferating root tissues appear to be sites of bone degradation, nutrient uptake and transport, whereas anterior portions of roots and the ovisac contain endosymbionts that appear to be degrading. How Osedax acquire their symbionts from the environment still remains unclear. Borrowing from a model developed for the vestimentiferan Riftia pachyptila, and evidence from FISH microscopy, Verna et al. [18] suggest that free-living bacteria in whale bones are translocated through the epidermis of proliferating Osedax roots. In contrast to Riftia, however, there appear to be repeated events of endosymbiont acquisition in Osedax.

\section{Conclusions}

Our analysis of cloned sequences from $16 S$ rRNA libraries indicated that we should expect essentially every Osedax individual to be infected with multiple ribotype strains of Oceanospirillales bacteria. In contrast, direct sequencing following PCR from Osedax tissues only revealed majority ribotypes infecting a particular tissue sample. PCR targets with low copy-number ( $\leq 30 \%)$ could not be detected with direct sequencing. The two methods present different costs and benefits, however. Time and funding often preclude the generation and screening of clone libraries from large time-series or numerous geographical samples. Nonetheless, cloning clearly provides a useful method for identifying the within-individual component of endosymbiont diversity. Though it sacrifices the within-individual component, and the level of multiple infections will most likely be underestimated, direct sequencing still provides an efficient method for screening the between-individual component of symbiont diversity in large population samples. New high-throughput screening methods provide a similar advantage for screening within-individual components of variance as does traditional cloning see for example [45]. And so as costs for these newgeneration methods continue to decline the tradeoffs 
involved in obtaining the within- and among-individual components of diversity should soon disappear.

\section{Competing interests}

The authors declare that they have no competing interests.

\section{Authors' contributions}

RS and RV designed the study and drafted the paper. RS participated in the sampling and dissection of Osedax hosts. She conducted the DNA purifications, cloning, sequence editing and analyses. RV performed most of the statistical analysis and drafted the figures. Both authors read and approved the final manuscript.

\section{Acknowledgements}

We are grateful to the captain and crew of RN Western Flyer and the pilots of ROVs Tiburon and Doc Ricketts for their excellent technical support. We thank Shannon Johnson for conducting the Bayesian phylogenetic analyses. The first author was supported by a grant from the Swiss National Science Foundation. The David and Lucile Packard Foundation provided direct funding for this project through grants to the Monterey Bay Aquarium Research Institute.

\section{Author details}

${ }^{1}$ Monterey Bay Aquarium Research Institute, Moss Landing, CA 95039, USA. ${ }^{2}$ Present Address: Department of Biology and Center of Infectious Disease Dynamics, The Pennsylvania State University, Millennium Science Complex, University Park, PA 16801, USA.

Received: 9 March 2012 Accepted: 19 September 2012

Published: 25 September 2012

\section{References}

1. Koslow T: The Silent Deep. Chicago: The University of Chicago Press; 2007.

2. Dubilier N, Bergin C, Lott C: Symbiotic diversity in marine animals: the art of harnessing chemosynthesis. Nat Rev Microbiol 2008, 6:725-740.

3. Vrijenhoek RC: Genetics and evolution of deep-sea chemosynthetic bacteria and their invertebrate hosts. The Vent and Seep Biota, Topics in Geobiology 2010, 33:201015-201050.

4. Bright M, Bulgheresi S: A complex journey: transmission of microbial symbionts. Nat Rev Microbiol 2010, 8:218-230.

5. Katz S, Klepal W, Bright M: The Osedax trophosome: organization and ultrastructure. Biol Bull 2011, 220:128-139.

6. Halanych KM, Feldman RA, Vrijenhoek RC: Molecular evidence that Sclerolinum brattstromi is closely related to vestimentiferans, not frenulate pogonophorans (Siboglinidae, Annelida). Biol Bull 2001, 201:65-75.

7. Rouse GW: A cladistic analysis of Siboglinidae Caullery, 1914 (Polychaeta, Annelida): formerly the phyla Pogonophora and Vestimentifera. Zoological Journal of the Linnean Society 2001, 132:55-80.

8. Rouse GW, Goffredi SK, Vrijenhoek RC: Osedax: Bone-eating marine worms with dwarf males. Science 2004, 305:668-671.

9. McMullin E, Hourdez S, Schaeffer SW, Fisher CR: Phylogeny and biogeography of deep sea vestimentiferans and their bacterial symbionts. Symbiosis 2003, 34:1-41.

10. Thornhill DJ, Wiley AA, Campbell AL, Bartol FF, Teske A, Halanych KM: Endosymbionts of Siboglinum fiordicum and the phylogeny of bacterial endosymbionts in Siboglinidae (Annelida). Biol Bull 2008, 214:135-144.

11. Goffredi SK, Orphan VJ, Rouse GW, Jahnke L, Embaye T, Turk K, Lee R, Vrijenhoek RC: Evolutionary innovation: a bone-eating marine symbiosis. Environ Microbiol 2005, 7:1369-1378.

12. Fujikura K, Fujiwara Y, Kawato M: A new species of Osedax (Annelida: Siboglinidae) associated with whale carcasses off Kyushu, Japan. Zoolog Sci 2006, 23:733-740

13. Glover AG, Käilström B, Smith CR, Dahlgren TG: World-wide whale worms? A new species of Osedax from the shallow north Atlantic. Proceedings of the Royal Society of London: Biological Sciences 2005, 272:2587-2592.

14. Rouse GW, Worsaae K, Johnson SB, Jones WJ, Vrijenhoek RC: Acquisition of dwarf male 'harems' by recently settled females of Osedax roseus n. sp. (Siboglinidae; Annelida). Biol Bull 2008, 214:67-82.
15. Vrijenhoek RC, Johnson SB, Rouse GW: A remarkable diversity of boneeating worms (Osedax; Siboglinidae; Annelida). BMC Biol 2009, 7:74. 13 pages.

16. Goffredi SK, Johnson SB, Vrijenhoek RC: Genetic diversity and potential function of microbial symbionts associated with newly discovered species of Osedax polychaete worms. Appl Environ Microbiol 2007, 73:2314-2323.

17. Miyazaki M, Nogi Y, Fujiwara Y, Kawato M, Kubokawa K, Horikoshi K. Neptunomonas japonica sp. nov., an Osedax japonicus symbiont-like bacterium isolated from sediment adjacent to sperm whale carcasses off Kagoshima, Japan. Int J Syst Evol Microbiol 2008, 58:866-871.

18. Verna C, Ramette A, Wiklund H, Dahlgren T, Glover A, Gaill F, Dubilier N: High symbiont diversity in the bone-eating worm Osedax mucofloris from shallow whale-falls in the North Atlantic. Environ Microbiol 2010, 12:2355-2370

19. Katz S, Klepal W, Bright M: The skin of Osedax (Siboglinidae, Annelida): An ultrastructural investigation of its epidermis. J Morphol 2010, 271:1272-1280.

20. Rouse GW, Wilson NG, Goffredi SK, Johnson SB, Smart T, Widmer C, Young CM, Vrijenhoek RC: Spawning and development in Osedax boneworms (Siboglinidae, Annelida). Mar Biol 2009, 156:395-405.

21. Nussbaumer AD, Fisher CR, Bright M: Horizontal endosymbiont transmission in hydrothermal vent tubeworms. Nature 2006, 441:345-348.

22. Rouse GW, Goffredi SK, Johnson SB, Vrijenhoek RC: Not whale-fall specialists, Osedax worms also consume fishbones. Biol Lett 2011, 7:736-739.

23. Stackebrandt E, Goebel BM: Taxonomic note: a place for DNA:DNA reassociation and $16 \mathrm{~S}$ rRNA sequence analysis in the present species definition in bacteriology. Int J Syst Bacteriol 1994, 44:846-849.

24. Day MD, Beck D, Foster JA: Microbial Communities as Experimental Units. Bioscience 2011, 61:398-406.

25. Braby CE, Rouse GW, Johnson SB, Jones WJ, Vrijenhoek RC: Bathymetric and temporal variation among Osedax boneworms and associated megafauna on whale-falls in Monterey Bay, California. Deep-Sea Res I Oceanogr Res Pap 2007, 54:1773-1791.

26. Lundsten L, Fraisier K, Schlining KL, Johnson SB, Kuhnz LA, Harvey JB, Clague G, Vrijenhoek RC: Time-series analysis of six whale-fall communities in Monterey Canyon, California, USA. Deep-Sea Res 1 Oceanogr Res Pap 2010, 57:1573-1584.

27. Jones WJ, Johnson SB, Rouse GW, Vrijenhoek RC: Marine worms (genus Osedax) colonize cow bones. Proceedings of the Royal Society of London: Biological Sciences 2008, 275:387-391.

28. Larkin M, Blackshields G, Brown N, Chenna R, McGettigan P, McWilliam H, Valentin F, Wallace I, Wilm A, Lopez R, et al: Clustal W and Clustal X version 2.0. Bioinformatics 2007, 23:2947-2948 [http://www.clustal.org/ clustal2/]

29. Maddison WP, Maddison DR: MacClade (Ver. 4.0): Computer Program for Phylogenetic Analysis. 4.08 edn. Sunderland, MA: Sinauer Associates, Inc; 2005 [http://macclade.org]

30. Tamura K, Peterson D, Peterson N, Stecher G, Nei M, Kumar S: MEGA5: Molecular Evolutionary Genetics Analysis using Maximum Likelihood, Evolutionary Distance, and Maximum Parsimony Methods. Mol Biol Evol 2011, 28:2731-2739 [http://www.megasoftware.net/]

31. Guindon S, Gascuel O: A simple, fast, and accurate algorithm to estimate large phylogenies by maximum likelihood. Syst Biol 2003, 52:696-704 [http://www.lirmm.fr/w3ifa/MAAS/]

32. Posada D: jModelTest: Phylogenetic Model Averaging. Mol Biol Evol 2008, 25:1253-1256 [http://darwin.uvigo.es/software/jmodeltest.html]

33. Huelsenbeck JP, Ronquist F: MRBAYES: Bayesian inference of phylogenetic trees. Bioinformatics 2001, 17:754-755 [http://bioinformatics.oupjournals. org/cgi/content/abstract/17/8/754 ]

34. Ronquist F, Huelsenbeck JP: MRBAYES 3: Bayesian phylogenetic inference under mixed models. Bioinformatics 2003, 19:1572-1574 [http://mrbayes. sourceforge.net/]

35. Rambaut A, Drummond A: Tracer 1.3. Oxford, UK: University of Oxford, Rambaut Research Group; 2003 [http://evolve.zoo.ox.ac.uk/]

36. Morariu V, Srinivasan BV, Raykar VC, Duraiswami R, Davis LS: Automatic online tuning for fast Gaussian summation. Advances in Neural Information Processing Systems (NIPS) 2008, [http://www.umiacs.umd.edu/ morariu/ figtree/] 
37. Clement M, Posada D, Crandall KA: TCS: a computer program to estimate gene genealogies. Mol Ecol 2000, 4:331-346.

38. JMP: ver 7. Cary, NC, USA: SAS Institute, Inc; 2007.

39. Nelson $\mathrm{K}$, Fisher C: Absence of cospeciation in deep-sea vestimentiferan tube worms and their bacterial endosymbionts. Symbiosis 2000, 28:1-15.

40. Agresti A: Categorical Data Analysis. New York: John Wiley; 1990.

41. Vrijenhoek RC, Johnson S, Rouse GW: Bone-eating Osedax females and their "harems" of dwarf males are recruited from a common larval pool. Mol Ecol 2008, 17:4535-4544.

42. Cohan FM: Bacterial species and speciation. Syst Zool 2001, 50:513-524.

43. Stackebrandt E, Frederiksen W, Garrity GM, Grimont PAD, Kämpfer P, Maiden MCJ, Nesme X, Rosselló-Mora R, Swings J, Trüper HG, et al: Report of the ad hoc committee for the re-evaluation of the species definition in bacteriology. Int I Syst Evol Microbiol 2002, 52:1043-1047.

44. Goffredi S, Wilpiszeski R, Lee R, Orphan V: Temporal evolution of methane cycling and phylogenetic diversity of archaea in sediments from a deepsea whale-fall in Monterey Canyon, California. ISME J 2008, 2:204-220.

45. Stewart FJ, Cavanaugh CM: Pyrosequencing analysis of endosymbiont population structure: co-occurrence of divergent symbiont lineages in a single vesicomyid host clam. Environ Microbiol 2009, 11:2136-2147.

doi:10.1186/1471-2148-12-189

Cite this article as: Salathé and Vrijenhoek: Temporal variation and lack of host specificity among bacterial endosymbionts of Osedax bone worms (Polychaeta: Siboglinidae). BMC Evolutionary Biology 2012 12:189.

\section{Submit your next manuscript to BioMed Central and take full advantage of:}

- Convenient online submission

- Thorough peer review

- No space constraints or color figure charges

- Immediate publication on acceptance

- Inclusion in PubMed, CAS, Scopus and Google Scholar

- Research which is freely available for redistribution 